\title{
Measurement of postoperative pericardial pressure in man
}

\author{
M. G. ST. JOHN SUTTON AND D. G. GIBSON \\ From the Cardiac Department, Brompton Hospital, Fulham Road, London
}

Pericardial pressure was measured in 18 patients undergoing cardiopulmonary bypass for up to 10 days using a solid state transducer. Mean and phasic pericardial pressure wave forms were similar to those reported in animals. $A$ wide range of mean pressure from 0 to $30 \mathrm{mmHg}$ was recorded, and values of up to $20 \mathrm{mmHg}$ were observed in patients whose postoperative clinical course was uncomplicated.

Fluctuations in pericardial pressure during spontaneous and artificial respiration were small, suggesting that concomitant left ventricular diastolic pressure changes were mainly the result of alterations in diastolic filling. Relative ventricular and pericardial distensibilities were estimated from the ratio of the slopes of diastolic pressure with time, which showed that up to 25 per cent of left ventricular diastolic pressure was supported by the pericardium and 75 per cent by the myocardium.

Measurement of pericardial pressure had clinical value in 2 patients in confirming and excluding the presence of pericardial tamponade.

Acute pericardial tamponade is a condition with a high mortality if untreated. It causes severe depression of cardiac function by limiting ventricular diastolic expansion (Starling, 1897; Isaacs et al., 1954; Holt et al., 1960; Pegram et al., 1975) and by reducing coronary flow leading to myocardial ischaemia (O'Rourke et al., 1967; Frank et al., 1971; Jarmakani et al., 1975). Its recognition after cardiac surgery may be delayed by difficulties in distinguishing it from depressed left ventricular function until the onset of severe hypotension. In spite of the clinical significance of this condition as a preventable cause of impaired cardiac function, there is very little information available in man about the normal pericardial pressure or its modification in the presence of tamponade. We have, therefore, taken advantage of the development of small stable solid state transducers to measure the pressure in the pericardium in patients after open heart surgery. The purpose of the investigation was to gain information about mean and phasic pericardial pressure in patients whose clinical course was uncomplicated and use this as a basis for the early diagnosis of tamponade. It was also possible to use the technique to make more general observations on pericardial pressure, and in particular to investigate its relation with airway pressure during spontaneous and artificial ventilation, and also with that of the left ventricular cavity during diastole. Received for publication 29 June 1976

\section{Methods}

Eighteen patients were studied during the postoperative period after cardiopulmonary bypass, usually for valve replacement. Clinical details are given in the Table. This investigation had the approval of the Ethics Committee of the National Heart and Chest Hospitals.

Pericardial pressure was measured with a Gaeltec 3EA solid state transducer. This had an external diameter of $3 \mathrm{~mm}$, low temperature sensitivity, and a resonant frequency of $50 \mathrm{kHz}$. The zero drift was low, and in the present study was found to be less than $2 \mathrm{mmHg}$ in 24 hours. It was calibrated in saline at $37^{\circ} \mathrm{C}$ before insertion and was used in conjunction with a Gaeltec S7 control unit amplifier with an isolated input.

The transducer was introduced into the pericardial space by a separate stab wound at the end of the operation and was left in situ for up to 10 days. The pericardium was closed once the transducer had been positioned. Several sites were used for the transducer placement, including posterior to the left atrium or left ventricle, and anterior to the right ventricle in order to study the effect of position. In all cases the zero for pressure measurement was taken as atmospheric.

Simultaneous electrocardiogram and external phonocardiogram were also recorded, and in 4 patients left ventricular pressure was recorded for 
Table Clinical details of patients studied

\begin{tabular}{|c|c|c|c|c|c|}
\hline $\begin{array}{l}\text { Case } \\
\text { No. }\end{array}$ & $\begin{array}{l}\text { Age } \\
(y)\end{array}$ & Sex & Rhythm & Diagnosis* & Operation * \\
\hline 1 & 28 & $\mathbf{F}$ & Sinus & AR & AVR Bj.S. \\
\hline 2 & 45 & $\mathbf{F}$ & A.fib. & $\mathrm{MS}+\mathrm{PHT}$ & MVR Bj.S. \\
\hline 3 & 44 & $\mathbf{F}$ & A.fib. & $\mathrm{MS}+\mathrm{PHT}$ & MVR Bj.S. \\
\hline 4 & 58 & $\mathbf{M}$ & Sinus & & AVR Bj.S. \\
\hline 5 & 45 & $M$ & A.fib. & $\mathrm{MVD}+\mathrm{PHT}$ & MVR Bj.S. \\
\hline 6 & 60 & $M$ & A.fib. & $\mathrm{AS}+\mathrm{MR}+\mathrm{PHT}$ & $\begin{array}{l}\text { MVR Bj.S. } \\
\text { AVR Bj.S. }\end{array}$ \\
\hline 7 & 36 & $\mathbf{F}$ & A.fib. & MVD & $\begin{array}{l}\text { MVR Bj.S. } \\
\text { TV plication }\end{array}$ \\
\hline 8 & 36 & $M$ & A.fib. & $\mathrm{MVD}+\mathrm{TR}+\mathrm{AR}$ & $\begin{array}{l}\text { MVR Bj.S. } \\
\text { TV plication }\end{array}$ \\
\hline 9 & 21 & $\mathbf{M}$ & Sinus & Fallot + ASD & $\begin{array}{l}\text { ASD closed; } \\
\text { correction of } \\
\text { Fallot }\end{array}$ \\
\hline 10 & 18 & $M$ & Sinus & MS + PHT & $\begin{array}{l}\text { M. valvotomy, } \\
\text { open }\end{array}$ \\
\hline 11 & 58 & $\mathrm{~F}$ & A.fib. & AVD + ASD & $\begin{array}{l}\text { ASD closed; } \\
\text { AVR Bj.S. }\end{array}$ \\
\hline 12 & 64 & F & A.fib. & $M S+M R$ & MV repair \\
\hline 13 & 61 & $M$ & Sinus & $\mathbf{A S}+\mathbf{A R}$ & $\begin{array}{l}\text { Aorta plicated } \\
\text { AVR Bj.S. }\end{array}$ \\
\hline 14 & 51 & $\mathbf{M}$ & Sinus & $\mathrm{AS}+\mathrm{AR}$ & AVR Bj.S. \\
\hline 15 & 33 & $\mathbf{M}$ & A.fib. & MS & $\begin{array}{l}\text { M. valvotomy + } \\
\text { repair }\end{array}$ \\
\hline 16 & 47 & $M$ & Sinus & $M S+M R$ & MVR Bj.S. \\
\hline 17 & 61 & $\mathbf{F}$ & A.fib. & MR & MV repair \\
\hline 18 & 29 & $\mathbf{M}$ & Sinus & AR & $\begin{array}{l}\text { MV repair } \\
\text { AVR Bj.S. }\end{array}$ \\
\hline
\end{tabular}

*AVR, aortic valve replacement; MVR, mitral valve replacement; Bj.S., Bjork-Shiley; TV plication, tricuspid valve plication; AR, aortic regurgitation; MS, mitral stenosis; PHT, pulmonary hypertension; MVD, mitral valve disease; AS, aortic stenosis.

12 to 24 hours after operation with a Millar No. 5 micromanometer left in the left ventricle at the time of surgery. Since this latter manometer exhibits appreciable zero drift over periods as short as several hours, it was not used to make absolute measurements of left ventricular pressure. All records were taken photographically, using the SE Instruments Emma recorder at paper speeds of 25 to $200 \mathrm{~mm}$ per second.

Mean and phasic pericardial pressure was recorded every 2 hours for the first 32 hours and daily thereafter, along with the electrocardiogram, phonocardiogram, and left ventricular pressure when available. When pericardial or mediastinal drains were still present, these were normally clamped before measurements were made. Observations were also made of the effects of unclamping the chest drains and of the relation with airway pressure during artificial ventilation, the latter being measured simultaneously at the level of the endotracheal tube. Relative left ventricular and pericardial distensibilities were derived from the ratio of the respective rates of increase of the two pressures during diastole.

There were no complications attributable to the investigation.

\section{Results}

\section{MEAN PRESSURES}

Changes in mean pericardial pressure with time after operation are shown in Fig. 1. On return to the intensive care unit, the mean value was in the range 4 to $8 \mathrm{mmHg}$ and remained so for the next 20 hours. However, at this time there was a consistent fall in mean pericardial pressure to less than $4 \mathrm{mmHg}$. This change, though small, was statistically significant $(P<0.01)$. In 5 patients there was an early rise in pericardial pressure to between 15 and $20 \mathrm{mmHg}$; in 1 patient, who developed tamponade, a value of $30 \mathrm{mmHg}$ was recorded. By 32 to 48 hours after operation, however, pericardial pressure was usually between 0 and $5 \mathrm{mmHg}$.

\section{PHASIC PRESSURE}

Phasic wave forms varied with mean pericardial pressure. When mean pressure was low, the overall amplitude of the wave form was small, but this increased when the mean level was greater than $10 \mathrm{mmHg}$. Regardless of the amplitude, however, the highest values in the cardiac cycle were recorded during isovolumic contraction reaching a peak which coincided with the onset of ejection. Pericardial pressure then fell and was at its lowest during late ejection or isovolumic relaxation, increasing again during ventricular filling (Fig. 2 and 3).

\section{REGIONAL VARIATION}

There was no effect on phasic or mean pressure attributable to the position of the transducer. An exactly similar increase in pericardial pressure occurred during ventricular isovolumic contraction when the transducer was posterior to the left atrium, as when it was related to the right or left ventricle.

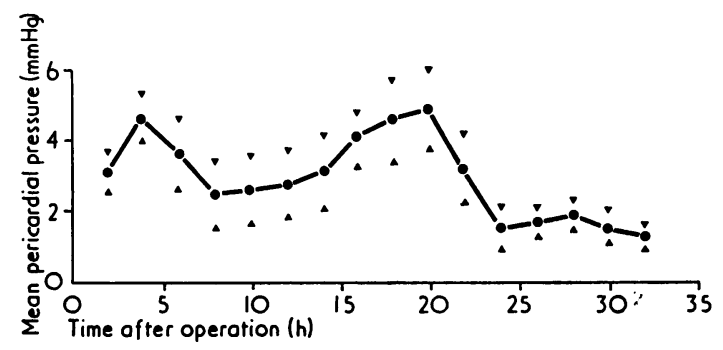

Fig. 1 Changes in mean pericardial pressure with time after the operation. Each point represents the mean value from all patients and standard errors of the mean are indicated. 


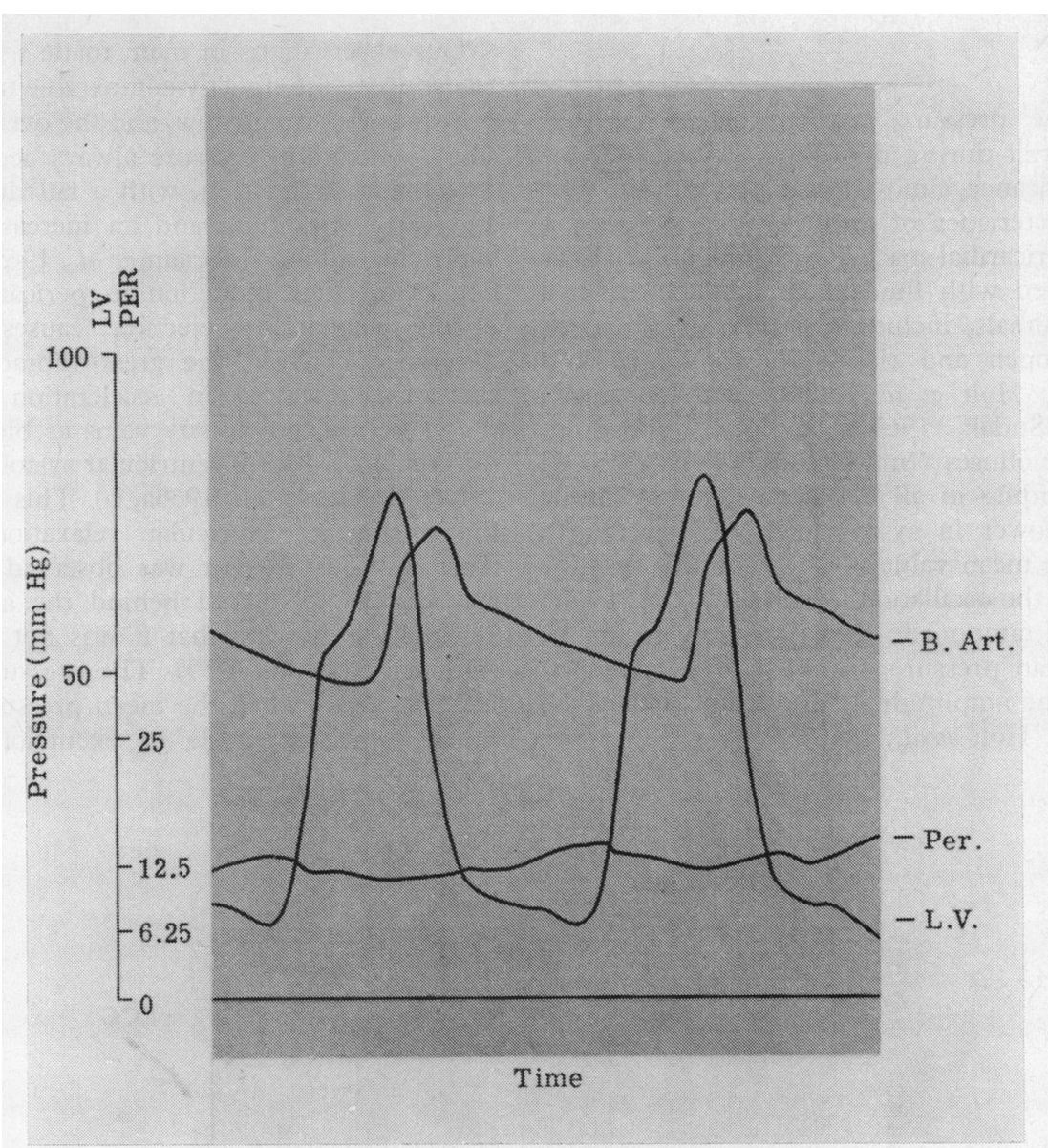

Fig. 2 Changes in phasic pericardial (Per) and left ventricular ( $L V)$ pressures during two cardiac cycles from Case 7. Brachial arterial pressure, measured with a fluid-filled manometer system, is also seen.

\section{AIRWAY AND LEFT VENTRICULAR}

\section{PRESSURE}

Fluctuations in pericardial pressure during spontaneous or artificial respirations were small, being less than $5 \mathrm{mmHg}$, though change in airway pressure was considerably greater. Unclamping the chest drains had no demonstrable effect on phasic or mean pressure. In 4 patients the relative rates of change of left ventricular and pericardial pressure, with respect to time during ventricular filling, were determined. The mean value of 10 determinations was $22 \mathrm{mmHg}$ per second for the pericardium and $90 \mathrm{mmHg}$ per second for the left ventricle, indicating that in these patients approximately 25 per cent of the diastolic left ventricular pressure was supported by the pericardium, rather than by the left ventricular wall itself (Fig. 4).

\section{CLINICAL ASSOCIATIONS}

In 16 patients, the clinical course was uncomplicated. In one patient, however (Case 6), in whom there were operative difficulties in achieving haemostasis, the initial mean pressure was $8 \mathrm{mmHg}$. Over the first 4 hours after operation, the mean pericardial pressure rose to $30 \mathrm{mmHg}$ and was associated with tachycardia and hypotension, confirming a clinical impression of tamponade. At reoperation, blood clot was evacuated from the pericardial space.

In another patient (Case 9) pericardial tamponade was suspected clinically on the basis of poor peripheral circulation, hypotension, tachycardia, and low urine flow, together with equally raised left and right atrial pressures. Pericardial pressure, however, was $1 \mathrm{mmHg}$ and, at operation, there was no evidence of tamponade. 


\section{Discussion}

Although the pressure gradient across the left ventricular wall during diastole is of considerable clinical significance, almost nothing is known in man of the characteristics of mean or phasic pressure within the pericardial space. Pericardial pressure has been measured with fluid-filled manometers in a variety of animals, including lightly anaesthetized dogs, both open and closed chest (Kenner and Wood, 1963; Holt et al., 1960; Shabetai et al., 1970), fish (Sudak, 1965), amphibia (Johansen, 1963), and molluscs (Smith and Davis, 1965). A consistent finding in all has been that pericardial pressure is lower in systole than in diastole. In the dogs, the mean value is 0 to $3 \mathrm{mmHg}$ and the amplitude of the oscillations low (Holt et al., 1960). Induction of tamponade leads not only to an increase in mean pressure, but also to a significant increase in the amplitude of oscillation during the cardiac cycle (Holt et al., 1960).
Our observations in man, made with solid state transducers, are directly comparable to these. Mean pressure was usually low, and the overall amplitude small. Maximum pressure always occurred during isovolumic contraction, with a fall during ejection and early relaxation, and an increase during left ventricular filling (Morgan et al., 1965; Shabetai et al., 1970). The reduction in pericardial pressure during ventricular ejection causes a pressure difference between the great thoracic veins and the atria, resulting in acceleration of blood in the cavae and pulmonary veins as blood is sucked into the atria during ventricular systole (Holt et al., 1960; Morgan et al., 1966a, b). This ensures rapid filling during ventricular relaxation and early diastole. This pattern was observed whether the transducer was placed behind the atrium or the ventricle, indicating that it was not a local effect (Duomarco et al., 1959). The pressure was modified, however, when the mean pressure was raised in that the amplitude of excursion during the

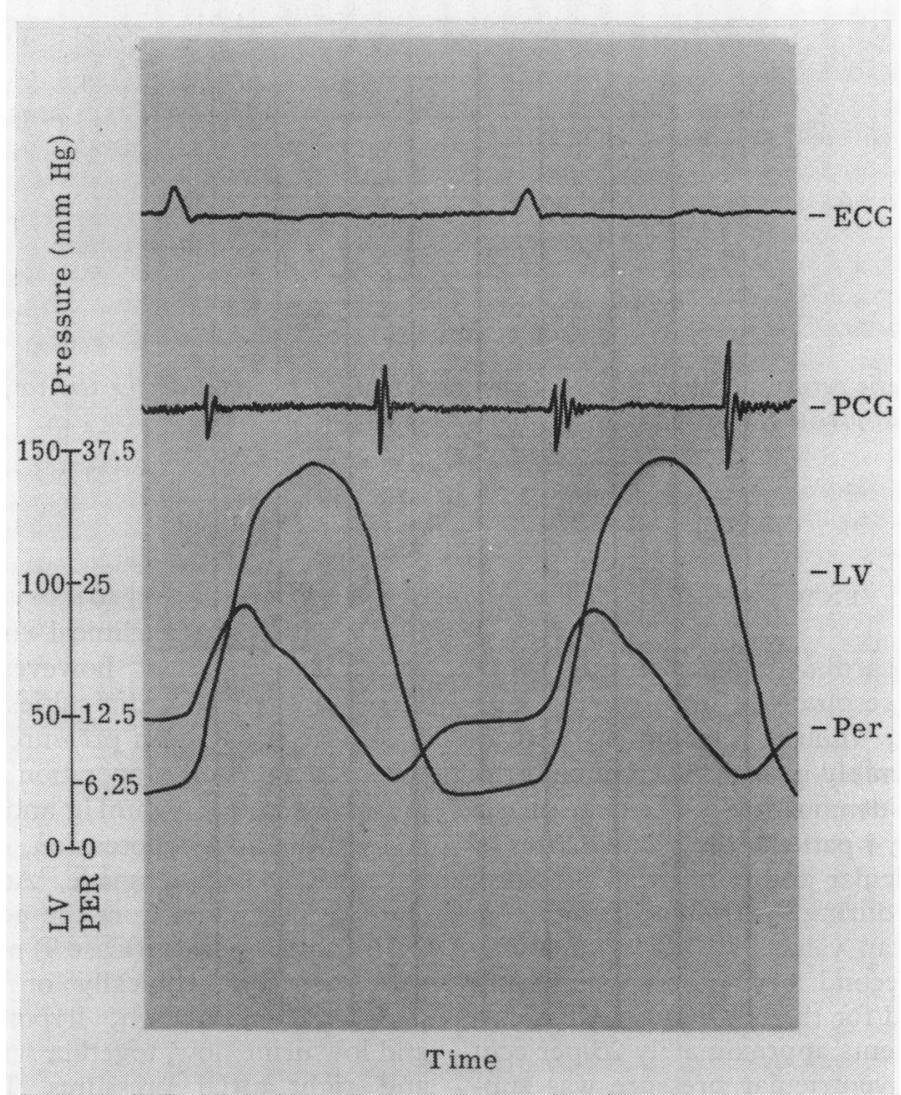

Fig. 3. Changes in phasic pericardial (Per) and left ventricular (LV) pressure during two cardiac cycles (Case 1). Electrocardiogram (ECG) and phonocardiogram (PCG) are also recorded. 


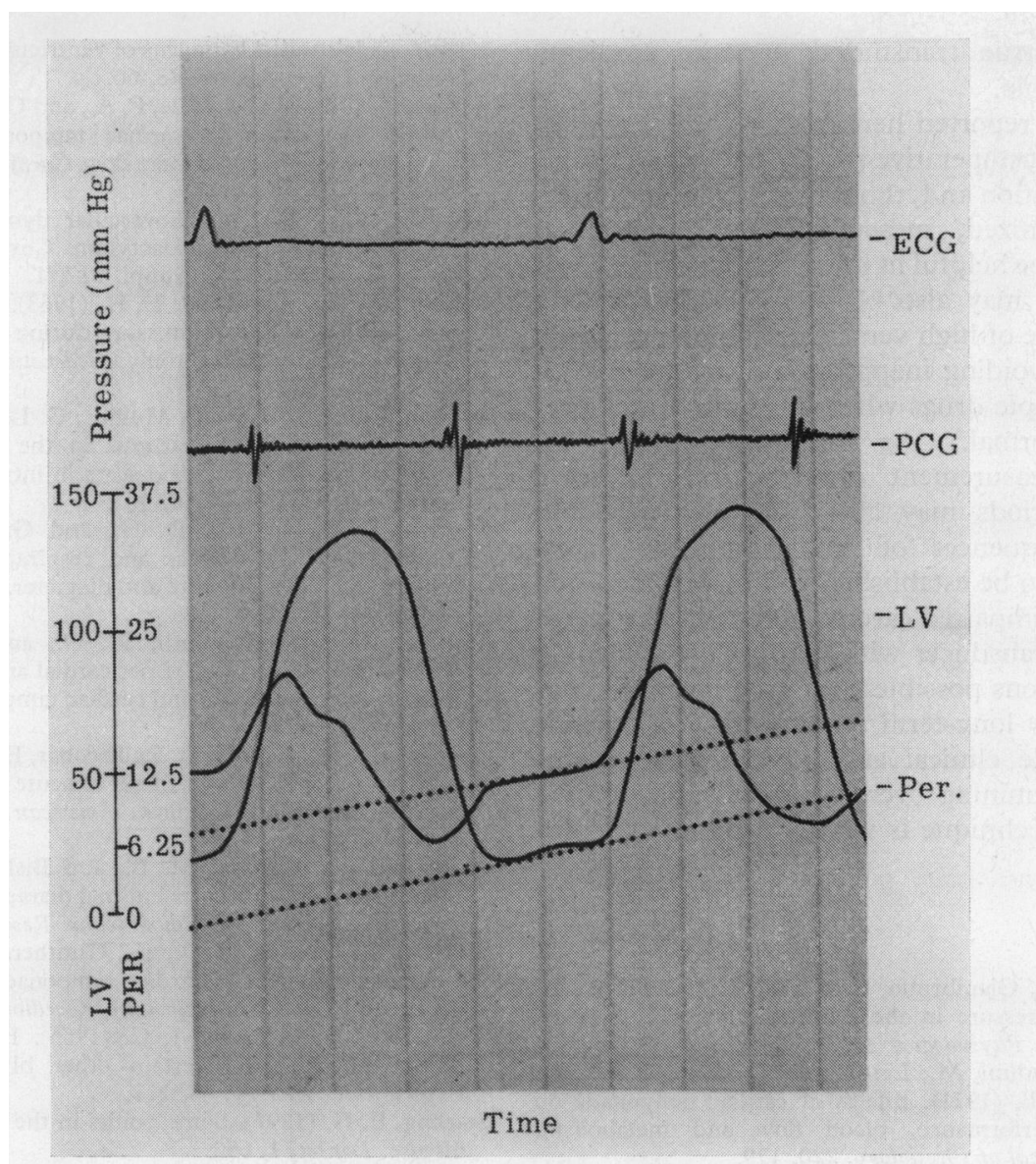

Fig. 4 Relative rates of change of left ventricular (LV) and pericardial (Per) pressure with time during diastole in Case 1. Electrocardiogram (ECG) and phonocardiogram (PCG) are also recorded.

cardiac cycle increased in a manner exactly comparable to that described in animal experiments (Holt et al., 1960). Several differences were apparent, however. Unlike the experiments of Holt et al. (1960), Kenner and Wood (1963), Morgan et al. (1965), Guntheroth et al. (1967), and Holt (1970), there appeared to be little connection between pericardial and airway pressure either during spontaneous or during artificial respiration, so the associated changes in left ventricular pressure probably reflected alterations in cavity volume. A second difference was the high resting pressure observed in 6 out of 18 patients whose clinical course was uncomplicated, suggesting that when the pericardium was closed after cardiac surgery, it may well be tight possibly because of the presence of tissue oedema.

The results reported here have a number of consequences for the assessment of cardiac function after open heart surgery. Right and left ventricular filling pressures are frequently monitored and are referred to an external reference point such as the sternal angle or mid-thorax. However, it cannot be assumed that they represent transmural pressures and they may be considerably raised after surgery solely because of raised pericardial pressure so that serious errors may arise if, for example, they are used to construct ventricular function curves. A second consequence is in the measurement of left ventricular pressure volume or stress/strain relations, where it is frequently assumed that the transmural left ventricular pressure is equivalent to that measured within the cavity. The present results show that the transmural pressure may be appreciably less than the value recorded in the cavity and not easily predictable from it. It seems, therefore, that conclusions about the diastolic properties of the left ventricular wall may well require modifi- 
cation when true transmural pressure gradients become available.

The results reported here may also have clinical significance. Postoperative pericardial tamponade is a serious condition and, though its advanced form is usually recognized, measurement of pericardial pressure may be helpful in its earlier detection. Such measurements may also be useful in determining the significance of high ventricular filling pressures, and thus of avoiding inappropriate treatment with positive inotropic drugs when transmural pressures are, in fact, normal.

Finally, measurement of pericardial pressure over long periods may allow the incidence and clinical consequences of late tamponade in its milder forms to be established and be distinguished from those of impaired cardiac function. The use of a solid state transducer with low drift would make such observations possible with little inconvenience and thus allow long-term monitoring of a variable of considerable clinical and physiological significance in determining overall cardiac function. We feel that the technique is worthy of more extended use.

\section{References}

Duomarco, J. L., Giambruno, C. E., and Correa Duran, A. (1959). The pressure in the different zones of the pericardium. Acta Physiologica Latino-Americana, 9, 267.

Frank, M. J., Nadimi, M., Lesniak, L. J., Hilmi, K. I., and Levinson, G. E. (1971). Effects of cardiac tamponade on myocardial performance, blood flow and metabolism. American Fournal of Physiology, 220, 179.

Guntheroth, W. G., Morgan, B. C., and Mullins, G. L. (1967). Effect of respiration on venous return and stroke volume in cardiac tamponade. Circulation Research, 20, 381.

Holt, J. P. (1970). The normal pericardium. American fournal of Cardiology, 26, 455.

Holt, J. P., Rhode, E. A., and Kines, H. (1960). Pericardial and ventricular pressure. Circulation Research, 8, 1171.

Isaacs, J. P., Berglund, E., and Sarnoff, S. J. (1954). Ventricular function. III. Pathologic physiology of acute cardiac tamponade studied by means of ventricular function curves. American Heart fournal, 48, 66.

Jarmakani, J. M. M., McHale, P. A., and Greenfield, J. C., Jr. (1975). The effect of cardiac tamponade on coronary haemodynamics in the awake dog. Cardiovascular Research, 9, 112.

Johansen, K. (1963). Cardiovascular dynamics in the amphibiar-Amphiuma, tridactylum Cuvier. Acta Physiologica Scandinavica, 60, Suppl. 217, 1.

Kenner, H. M., and Wood, E. H. (1963). Pericardial, intrapleural and intracardiac pressure during acute heart failure in dogs without thoracotomy. Federation Proceedings, 22, 459.

Morgan, B. C., Abel, F. L., Mullins, G. L., and Guntheroth, W. G. (1966a). Flow patterns in the cavae, pulmonary artery, pulmonary veins and aorta in intact dogs. American Fournal of Physiology, 210, 903.

Morgan, B. C., Dillard, D. H., and Guntheroth, W. G. (1966b). Effect of cardiac and respiratory cycle on pulmonary vein flow, pressure and diameter. Fournal of Applied Physiology, 21, 1276.

Morgan, B. C., Guntheroth, W. G., and Dillard, D. H. (1965). The relationship of pericardial and pleural pressure during quiet respiration and cardiac tamponade. Circulation Research, 16, 493.

O'Rourke, R. A., Fischer, D. P., Escobar, E. E., Bishop, V. S., and Rapaport, E. (1967). Effect of acute pericardial tamponade on coronary blood flow. American fournal of Physio$\log y, 212,549$.

Pegram, B. L., Kardon, M. B., and Bishop, V. S. (1975). Changes in left ventricular internal diameter with increasing pericardial pressure. Cardiovascular Research, 9, 707.

Shabetai, R., Fowler, N. O., and Guntheroth, W. G. (1970). The hemodynamics of cardiac tamponade and constrictive pericarditis. American fournal of Cardiology, 26, 480.

Smith, L. S., and Davis, J. C. (1965). Haemodynamics in Tresus nuttallii and certain other bivalves. Fournal of Experimental Biology, 43, 171.

Starling, E. H. (1897). Some points in the pathology of heart disease. Lancet, 1, 652.

Sudak, F. N. (1965). Intrapericardial and intracardiac pressures and events of the cardiac cycle in Musteluscanis (Mitchill). Comparative Biochemistry and Physiology, 14, 689.

Requests for reprints to Dr. M. G. St. John Sutton, Cardiac Department, Brompton Hospital, Fulham Road, London SW3 6HP. 